\title{
Antigiardial activity of some plant extracts used in traditional medicine in Sudan in comparison with metronidazole.
}

\author{
Kayondo Najumudin*, Jumaa Ayubu, Anas M. Elnazeer \\ Department of Microbiology, Faculty of Pure and Applied Sciences, International University of Africa Khartoum \\ Sudan, Uganda
}

\begin{abstract}
Giardiasis is one of the common parasitic diarrhoea in humans especially in children worldwide. Many drugs are used for its treatment but there is evidence of drug resistance, insufficient efficacy and unpleasant side effects. Natural products are good candidates for discovering more effective antigiardial compounds. The aim of this study was to investigate the in vitro antigiardial activity of ethanolic extracts of Solennostemma argel, Trigonella foenum graecum and Mentha $x$ piperita in comparison with metronidazole. Giardia trophozoites were isolated from feacal samples. The ethanolic extracts of 3 plants with concentration of $5000 \mathrm{ppm}$ were investigated together with metronidazole (positive control) at $0.3125 \mathrm{ppm}$ against $G$. lamblia trophozoites. The extracts of 3 plants were incubated at $37^{\circ} \mathrm{C}$ for $24,48,72$ and $96 \mathrm{~h}$. Mortality of trophozoites was observed by $0.4 \%$ Trypan blue and a haemocytometer. Trigonella foenum graecum, Mentha $x$ piperita and Solennostemma argel exhibited $98 \%, 92 \%$ and $65 \%$ mortality respectively within $96 \mathrm{~h}$ at concentration of $5000 \mathrm{ppm}(5 \mathrm{mg} /$ $\mathrm{ml})$. This was compared to metronidazole which gave $100 \%$ inhibition at concentration of $0.3125 \mathrm{ppm}$ at the same time. The ethanolic extracts of Trigonella foenum graecum, Solennostemma argel and Mentha x piperita had potent antigiardial activity. This will provide natural therapeutic treatment to giardiasis with minimal side effects and drug resistance. We recommend using these plants against Giardia lamblia in the in vivo and also to find fractions of the pharmacological effects of these plants.
\end{abstract}

Keywords: Giardia lamblia; Solennostemma argel; Trigonella foenum graecum; Mentha x piperita; Metronidazole. Accepted on November 04, 2018

\section{Introduction}

Giardia lamblia is a parasite that colonizes the duodenum and upper jejunum of humans causing a disease known as giardiasis $[1,2]$. It causes public health problems in most developing countries as well as some developed countries [3-5].

The emergence and spread of Giardiasis in human population is an increasing problem around the world, especially in developing countries. Giardiasis has been also included as "Neglected Disease" by WHO, but it is not reported by many countries of the world [6-9].

For the treatment of Giardiasis Metronidazole as the first choice and other drugs; Tinidazole, Albandazole, Furazolidone are also used [10-13]. Undesirable side effects and failures in treatment and drug resistance are frequently reported $[8,10,13]$. For example, side effects of Metronidazole include nausea, loss of appetite, vomiting, diarrhea, lethargy, weakness, anemia, blood in the urine, head tilt, seizures, disorientation, and stumbling. It may also cause liver disease, which can result in yellowing of the gums, skin, and eyes. Damage to nerves is also possible and the mutagenic effects of this drug in some bacteria and animal models were confirmed [13-16].

For centuries, people have long been living in close association with the environment and using its flora and fauna as a source of food and medicine and many societies have their own rich plant pharmacopeias. Plants are good source of therapeutic compounds and play a vital role in health care system [17].

Current estimates suggest that, in many developing countries, a large proportion of the population relies heavily on traditional practitioners and medicinal plants to meet primary health care needs [9].

The aim of this study was to assess the in vitro antigiardial activity of ethanolic plant extracts of Mentha x piperita Lin, Trigonella foenum graecum and Solennostemma argel used in traditional medicine in Sudan in comparison with metronidazole.

Peppermint (Mentha $x$ piperita), also known as Mentha balsamea Willd [18] is a hybrid mint: a cross between watermint and spearmint [19]. Peppermint oil vapour is used as an inhalant for respiratory congestion. Peppermint tea is used to treat coughs, bronchitis, and inflammation of the oral mucosa and throat. It has traditionally been used to treat a variety of digestive complaints such as colic in infants, flatulence, diarrhoea, indigestion, nausea and vomiting, morning sickness and anorexia, and as a spasmolytic to reduce gas and cramping [20].

Trigonella foenum-graecum is an annual plant in the family Fabaceae, with leaves consisting of three obovate to oblong [21]. Trigonella is an ancient plant indigenous to Sudan and used as Anabolic agent, antibiotic, antidiabetic, antifatigue, 
Citation: Najumudin K, Ayubu J, Elnazeer AM. Antigiardial activity of some plant extracts used in traditional medicine in Sudan in comparison with metronidazole. Microbiol Curr Res. 2018;2(4):75-82.

antimicrobial antihyperglycaemic, antihypertensive, antiinflammatory, antioxidant, antipyretic, antiseptic, antispasmodic, aphrodisiac, astringent, carminative, cancerolytic, digestive cardiotonic, demulcent, diaphoretic, digestive, disinfectant, emmenagogue, emollient, expectorant, galactagogue, haemopoietic, hypolipidemic, lactogenic, laxative, neuromuscular stimulant, nutritive, stomachic, tonic, uterotonic, vulnerary, viricidal, stimulatory effect on immune function, antioxidant properties, protection against toxicity and for avarity kidney disorder [4].

Solenostemma argel (Argel) known locally by the name (Hargel) and scientifically known as Solenostemma argel is a plant in the "Apocynaceae" family. It is indigenous to Africa. The parts used are the leaves and stems; the leaves contain high carbohydrates and protein as well as crude oil, ash, calcium and magnesium [22]. Harjal leaves are used in indigenous medicine for the treatment of some diseases such as the disease of liver and kidney [23]. It is an effective remedy for bronchitis and is used to treat neuralgia. It is used as incense in the treatment of measles and sometimes crushed and used as remedy for healing wounds. The leaves are infused to treat gastro-intestinal cramps and stomach colic [23].

\section{Material and Methods}

\section{Plant materials}

Trigonella Foenum Graecum (seeds), Solennostemma argel and Mentha x piperita were bought from Souk Sinia Markaz market in Khartoum state on 03/01/2017. The plant materials were cleaned with removal of foreign materials like stones by hands. The plant materials were kept in air tight clean polythene bags ready for preparation.

\section{Preparation of plant materials}

Solennostema argel and menthe $\mathbf{x}$ piperita: The leaves were washed first under running tap water, followed by sterilized distilled water and dried for $5 \mathrm{~d}$ at room temperature in dark then grinded to powder using an electrical blender.

Fenugreek seeds (Trigonella foenum): The seeds then grinded to powder using and electric blender. The ground plant materials were placed in air tight plastic bags and stored in the laboratory for extraction process.

\section{Preparation of crude extracts}

Extraction was carried out for the powder of three plants Solennostemma argel, Trigonella foenum graecum and Mentha $x$ piperita Lin. (Lamiaceae) by using cold maceration techniques. $50 \mathrm{~g}$ of ground plant extracts were weighed on sensitive balance. The three (3) weighed ground plants each were placed in three separate conical flasks with addition of $500 \mathrm{ml}$ of $80 \%$ ethanol. The three conical flasks then stoppered. The stoppered flasks with the ethanol were to stand at room temperature $\left(25^{\circ} \mathrm{C}\right)$ for $24 \mathrm{~h}$ in shaker with frequent agitation until the soluble matter has dissolved. After $24 \mathrm{~h}$, the mixture was shaken well and filtered with clean sterile cotton wool into a beaker. The filtrate was poured in large Petri dishes and allowed to stand for $3-5 \mathrm{~d}$ at room temperature to evaporate off the ethanol. The dried extract was scratched off the petri dishes and stored in vial tubes at $4^{\circ} \mathrm{C}$ for phytochemical screening and in vitro susceptibility procedures.

\section{Preparation of human serum}

The serum prepared using modified method of [24]; $10 \mathrm{ml}$ of Blood were collected under antiseptic conditions from individual of type $\mathrm{O}$ and drawn into blood tubes using syringe. Blood tubes centrifuged at $2500 \mathrm{rpm}$ for $10 \mathrm{~min}$ at room temperature. Tubes were removed from the centrifuge and transferred to the laminar flow. The tubes were opened to access the serum located at the top of the specimen. Using a sterile pipette, $1.5 \mathrm{ml}$ of serum was transferred into labelled cryovial tube. The collected serum was used immediately in culturing the G. lamblia.

\section{Parasite isolate}

G. lamblia used in all experiments were taken from fecal samples collected from patients presented to Bashayir Hospital Khartoum-Sudan January 2017. All taken samples were examined by wet amount preparation; the positive samples were transported to the laboratory in suitable medium. Trophozoites of G. lamblia were maintained in thioglycollate medium containing human serum at $37 \pm 1^{\circ} \mathrm{C}$. The trophozoites were maintained for the assays and were employed in the log phase of growth.

\section{In vitro susceptibility assays}

In vitro susceptibility assays were performed following the modified sub-culture method by Cedillo-Rivera et al. [25], which is being described as a highly stringent and sensitive method for assessing the anti-protozoal effects (gold standard) particularly in E. histolytica, Gairdia intestinalis and Trichomonas vaginalis [26]. $5 \mathrm{mg}$ from each extract and compound was dissolved in $50 \mu \mathrm{l}$ of dimethyl sulfoxzide (DMSO) at Eppendorf tube containing $950 \mu \mathrm{l}$ sterile distilled water in order to reach concentration of $5 \mathrm{mg} / \mathrm{ml}(5000 \mathrm{ppm})$. The concentrates were stored at $-20^{\circ} \mathrm{C}$ for further analysis. Sterile 96-well microtitre plate was used for different plant extracts, positive control and negative control. Three columns of a microtitre plate wells $(8$ columns $(\mathrm{C}) \times 12$ rows $(\mathrm{R}))$ were chosen for each extract, $80 \mu \mathrm{l})$ of an extract solution $(5 \mathrm{mg} / \mathrm{ml})$ were added to the first column wells C-1: On the other hand, $40 \mu \mathrm{l}$ of complete thiolglycolate medium were added to the other wells of the second column and third column (C-2 and C-3). Serial dilutions of the extract were obtained by taking 40 $\mu \mathrm{l}$ of extract to the second column wells and taking $40 \mu \mathrm{l}$ out of the complete solution in C-2 wells to C- 3 wells and discarding $40 \mu \mathrm{l}$ from the total solution of C-3 to the remaining $20 \mu \mathrm{l}$ serial solutions in the successive columns. $160 \mu \mathrm{l}$ of culture medium was complemented with parasite and added to all wells. The final volume in the wells was $200 \mu$. The 96 well microtitre plate was placed in a shaker and incubated at $37^{\circ} \mathrm{C}$.

In each test, Metronidazole (a trichomonocide) pure compound ((1-(2-hydroxyethl)-2-methyl-5 Nitroimidazole), was used as positive control in concentration $312.5 \mu \mathrm{g} / \mathrm{ml}$, whereas 
untreated cells were used as a negative control (culture medium plus trophozoites). For counting, the samples were mixed with eosin red in equal volume. The final number of parasites was determined with haemocytometer four times for counting after $24,48,72$ and $96 \mathrm{~h}$. The percentage mortality of parasite for each extracts activity was carried out according to the following formula:

Mortality of parasites $(\%)=(($ Control negative-tested sample with extract $) /($ control negative $)) \times 100 \%$

Equation key: Control negative=Number of dead Giardia lamblia organisms in the negative control.

Tested with sample=Number of dead organisms in respect with different plant sample extracts

Only $100 \%$ inhibition of the parasite was considered, when there was no motile parasite observed.

\section{Counting using Neuberer Chamber}

Cell counts were done using the improved Neubauer chamber. The cover slip and chamber were cleaned with detergent, rinsed thoroughly with distilled water and swapped with $70 \%$ ethanol, then dried. An aliquot $10 \mu \mathrm{l}$ of cell suspension was mixed with equal volume of $0.4 \%$ Trypan blue in a small tube. The chamber was charged with cell suspension. After cells had settled, the chamber was placed under light microscope. Using $40 \mathrm{X}$ objective, cells in the 4 large corner squares (each containing 16 small squares) were counted.

\section{Results and Discussion}

The antigiardial potential of the ethanolic extract of Solennostemma argel, Trigonella foenum graecum and Mentha $x$ piperita Lin. with concentrations $5000 \mathrm{ppm}(5 \mathrm{mg} / \mathrm{ml})$ and Metronidazole (the positive control) with concentration of $0.3125 \mathrm{ppm}$ was investigated against $G$. lamblia trophozoites in vitro.

In the present work, we have tested 3 extracts from 3 Sudanese medicinal plants against in vitro growth of Giardia lamblia in comparison with metronidazole. The ethanol extract from Trigonella foenum graecum exhibited the best activity against in vitro growth of $G$. intestinalis (Table 1 and Figure 1). Thus medicinal plants are still invaluable source of safe, less toxic, lower price, available and reliable natural resources of drugs all over the world [27].
Extract of Trigonella foenum graecum was the most active against the Giardia lamblia trophozoites for all the hours of exposure with mortality rate of $88,88,92$ and $98 \%$ for 24,48 , 72 and $96 \mathrm{~h}$ respectively and showed 98\% inhibition of Giardia lamblia after $96 \mathrm{~h}$ of exposure (Table 1 and Figure 1) .This result is similar or near to agree with a result obtained by Ahmed et al. [4] in Khartoum Sudan reported that antigiardial activity of ethanolic seed extract of Trigonella foenum graecum established by subculture method of CedilloRivera et al. [25]. Ethanol extracts of Trigonella foenum graecum showed 100\% inhibition of giardia trophozoites at 96 $\mathrm{h}$ in comparison with $96 \%$ inhibition of metronidazole at same time.

On the other hand, the extract of Mentha $x$ piperita exhibited moderate activity against Giardia lamblia trophozoites with mortality rate of $79,86,88$ and $92 \%$ for $24,48,72$ and $96 \mathrm{~h}$ respectively. There are other works performed by Vidal et al. [1] in Rio de Janaeiro Brazil on the effects of extracts and fractions from Mentha $x$ piperita Lin. (Lamiaceae) on trophozoites using adherence inhibition assays exhibited activity against $G$. lamblia trophozoites. It is supportive of our finding.

Extract of Solennostemma argel showed the lowest activity against Giardia lamblia trophozoites of all the 3 plant extracts with mortality rate of $58,47,59$ and $59 \%$ for $24,48,72$ and 96 $\mathrm{h}$ respectively.

There is no similar study conducted on Solennostemma argel as antigiardial but there is some study done by Sulieman et al. [23] suggested that Solennostemma argel as a treatment for gastro-intestinal cramps.

Metronidazole (positive control) also showed high activity against Giardia lamblia trophozoites and its mortality rate was slightly higher than extract of Trigonella foenum graecum. Metronidazole exhibited mortality of 89, 91, 93 and 100\% with exposure time of $24,48,72$ and $96 \mathrm{~h}$ respectively. $100 \%$ inhibition of trophozoites showed after $96 \mathrm{~h}$ of exposure.

In control negative, there was low motility rate for first $48 \mathrm{~h}$. Later mortality gradually increased with time of exposure. The mortality was $0,5,20$ and $32 \%$ for $24,48,72$ and $96 \mathrm{~h}$ respectively. According to growth dynamics of microorganisms, when an organism is introduced into fresh culture medium, it tends to take some time to adjust thus passing through lag, logarithmic, stationary and decline phases.

Table 1: The antigiardial activities of $S$. argel, T. foecum and Mentha x piprita ethanolic plant extracts.

\begin{tabular}{|c|c|c|c|c|c|}
\hline \multirow{2}{*}{ Time/hours } & \multicolumn{5}{|c|}{ Mortality \% } \\
\hline & S. argel & T. foenum & Mentha $x$ piperita & Negative control & Positive control \\
\hline 24 & 58 & 88 & 79 & 0 & 89 \\
\hline 48 & 47 & 88 & 86 & 5 & 91 \\
\hline 72 & 59 & 92 & 88 & 20 & 93 \\
\hline 96 & 65 & 98 & 92 & 32 & 100 \\
\hline
\end{tabular}


Citation: Najumudin K, Ayubu J, Elnazeer AM. Antigiardial activity of some plant extracts used in traditional medicine in Sudan in comparison with metronidazole. Microbiol Curr Res. 2018;2(4):75-82.

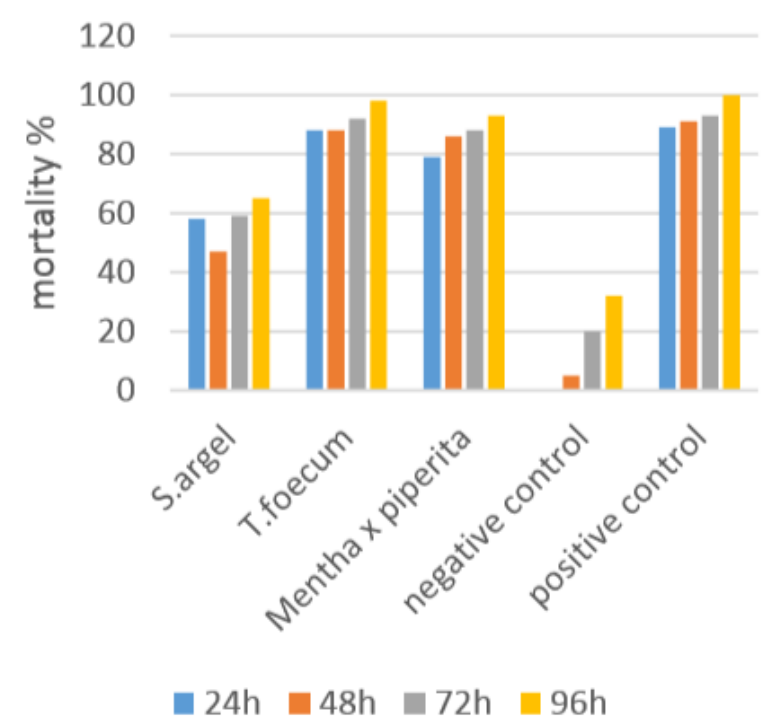

Figure 1: A graph of in vitro antigiardia activity of Solennostemma argel, Trigonella foenum graecum, Mentha $x$ piperita, negative control and positive control (metronidazole).

Metronidazole remains a preferable drug for the treatment of giardiasis though it can be substituted with Trigonella foenum graecum because it had almost same activity against giardia basing on the study results. Metronidazole is the first drug of choice recommended by the World Health Organization (WHO) for amoebiasis and giardiasis treatment [28]. However it has adverse side effects for example nausea, loss of appetite, vomiting, diarrhoea, lethargy, weakness, anemia, blood in the urine, head tilt, seizures, disorientation, and stumbling of metronidazole reported by Gholami et al. [9].

\section{Conclusion}

This study suggested that extract from Trigonella foenum graecum seems to be a good candidate for use against giardial infections. But to be used on animals and human it should be further investigated in vivo before being used as antiprotozoal parasite in human.

\section{Acknowledgement}

The authors are thankful to International University of Africa, Faculty of Pure and Applied Sciences, Department of Microbiology for providing necessary facilities and cooperation during this research work.

\section{References}

1. Vidal F, Vidal JC, Gadhela AP, et al. Giardia lamblia: The effects of extracts and fractions from Mentha $\mathrm{x}$ piperita Lin. (Lamiaceae) on trophozoites. Exp Parasitol. 2007;115:25-31.

2. Gardner TB, Hill DR. Treatment of giardiasis. Clin Microbiol Rev. 2001;14:114-28.

3. Addy PA, Antepim G, Frimpong EH. Prevalence of pathogenic Escherichia coli and parasites in infants with diarrhoea in Kumasi, Ghana. East Afr Med J. 2004;81:353-7.

4. Ahmed SK, Arwa MH, Ahmed OS, et al. Antigiardial activity and cytotoxicity of ethanolic seed extract of Trigonella Foenum Graecum L. Int J Multidiscip Res Dev. 2015;2:49-52.

5. Dib HH, Lu SQ, Wen SF. Prevalence of Giardia lamblia with or without diarrhea in South East, South East Asia and the Far East. Parasitol Res. 2008;103:239-51.

6. Gholami S, Kyanyan H, Mobedi I. Intestinal Protozoan Infections in cattle breeders in rural regions of Mazandaran province in 2003. Nameh daneshgah. J Mazandaran University Med Sci. 2005;45:51-60.

7. Lane S, Lloyd D. Current trends in research into the waterborne parasite Giardia. Crit Rev Microbiol. 2002;28: 123-47.

8. Savioli L, Smith H, Thompson A. Giardia and Cryptosporidium join the 'Neglected Diseases Initiative'. Trends Parasitol. 2006;22: 203-8.

9. Gholami S, Azadbakht M, Hezarjaribi HZ, et al. AntiGiardial Activity of Chloroformic Extract of Tanacetum parthenium and Artemisia annua in vitro. Res Mol Med. 2014;2:45-50.

10. Alizadeh A, Ranjbar M, Kashani KM, et al. Albendazole versus metronidazole in the treatment of patients with giardiasis in the Islamic Republic of Iran. East Mediterr Health J. 2006;12:548-54.

11. Brandelli CL, Giordani RB, De Carli GA, et al. Indigenous traditional medicine: in vitro anti-giardial activity of plants used in the treatment of diarrhea. Parasitol Res. 2009;104:1345-9.

12. Moerch K, Hanevik K, Robertson LJ, et al. Treatmentladder and genetic characterization of parasites in refractory giardiasis after an outbreak in Norway. J Infect. 2008;56:268-73.

13. Tracy J, Webster L Jr. Drugs used in the chemotherapy of protozoal infection. Ninth ed. Goodman \& Gilman's The Pharmacological Basis of Therapeutics, ed. J.G. Hardman and L.E. Limbird. Vol. 987-1008. 1996, New York: McGraw-Hill.

14. Johnson PJ. Metronidazole and drug resistance. Parasitol Today. 1993;9:183-6.

15. Lemee V, Zaharia I, Nevez G, et al. Metronidazole and albendazole susceptibility of 11 clinical isolates of Giardia duodenalis from France. $\mathrm{J}$ Antimicrob Chemother. 2000;46:819-21.

16. Voolmann Y, Boreham P. Metronidazole resistant in Brisbane. Med J Australia. 1993;159- 490.

17. Abdelazim AA, Howladar SM, Al-Gadir Mohamed HA, et al. Phytochemistry, Antimicrobial, Antigiardial and Antiamoebic Activities of Selected Plants from Albaha Area, Saudi Arabia. Br J Med Med Res. 2016;18:1-8.

18. WHO, WHO Monographs on Selected Medicinal Plants. World health organisation Geneva. 2002; 2:188-99.

19. Frampton A. The Complete Illustrated Book of Herbs. The Reader's Digest Association. 2009. 
20. Fleming T. PDR for herbal medicines. Medical Economics Company, Inc: Montvale, NJ. 1998.

21. NPGS, n.p.g.s. trigonella foenum graecum information from NPGS/GRIN. 2008.

22. Sabah El-Kheir MK. Chemical Composition, Minerals, Protein Fractionation, and Anti-nutrition Factors in Leaf of Hargel Plant (Solenostemma argel). Euro J Publishing Inc. 2010;43:430-4.

23. Sulieman AME, Elzobair WM, Abdelrahim AM. Antimicrobial activity of the extract of Solenostemma argel (harjal) plant. J Sc Tech. 2009;10:120-34.

24. Takahashi M, Makino S, Kikkawa T, et al. Preparation of Rat Serum Suitable for Mammalian Whole Embryo Culture. J Vis Exp. 2014;90:e51969.

25. Cedillo-Rivera R, Chavez B, González-Robles A, et al. In vitro effect of nitazoxanide against Entamoba histolytica, Gairdia lamblia and vaginalis trophozoites. J Eukaryot Microbiol. 2002;49:201-8.

26. Arguello-Garcia R, Cruz Soto M, Romero Montoya L, et al. Variability and variation in drug susceptibility among
Giardia duodenalis isolates and clones exposed to 5nitromidazoles and benzimidazoles in vitro. J Antimicrob Chemother. 2004;54:711-21.

27. Amaral FMM, Ribeiro MNS, Barbosa-Filho JM, et al. Plants and chemical constituents with giardicidal activity. Braz J Pharmacog. 2006;16:696-720.

28. Gonzales MLM, Dans LF, Martinez EG. Antiamoebic drugs for treating amoebic colitis (Review). Cochrane Database Syst Rev. 2009;15:1-132.

\section{Correspondence to:}

Kayondo Najumudin

Department of Microbiology,

Faculty of Pure and Applied Sciences,

International University of Africa Khartoum Sudan, Uganda

E-mail: knajumudin@gmail.com 